\title{
Gestão de pessoas e relações de trabalho: análise da produção científica publicada nos anais dos ENGPR
}

Nos últimos anos, as pesquisas sobre o desenvolvimento das organizações têm tratado de forma concatenada os temas relacionados à gestão de pessoas e às relações de trabalho, de modo a evidenciar a importância existente nas duas áreas de estudo da administração. Nesse contexto, o presente trabalho revela o resultado da análise dos artigos publicados nos anais dos EnGPR - Encontro de Gestão de Pessoas e Relações de Trabalho, promovido bienalmente pela ANPAD - Associação Nacional de Pós-Graduação e Pesquisa em Administração, até a edição 2013. Como principais resultados, observou-se a predominância de estudos relacionados às convergências entre gestão de pessoas, relações de trabalho e comportamento organizacional e sobre prazer e sofrimento no trabalho, com ênfase metodológica nos estudos empíricos, de abordagem qualitativa, por meio de estudos de caso. A maioria dos trabalhos adveio de pesquisadores da região Sudeste e as referências nacionais foram as mais usadas pelos estudos. Dessa forma, foi possível, a partir das conclusões do trabalho, traçar um panorama geral da produção acadêmica sobre a temática dos campos de gestão de pessoas e relações de trabalho, além de ilustrar os temas de interesse dos pesquisadores e a estrutura metodológica dos trabalhos na área.

Palavras-chave: Análise; Produção Científica; Gestão de Pessoas; Relações de Trabalho.

\section{Personnel management and labor relations: analysis of scientific production published in the annals of ENGPR}

\begin{abstract}
In recent years, research on organizations development have approached with concatenated manner issues related to personnel management and labor relations, in order to show the importance of both management areas of study. In this context, this paper reveals the result of the analysis of articles published in the Annals of EnGPR - Encontro de Gestão de Pessoas e Relações de Trabalho, sponsored every two years by ANPAD - Associação Nacional de Pós-Graduação e Pesquisa em Administração. As main results, there was a predominance of studies related to similarities between personnel management, labor relations and organizational behavior as well as pleasure and suffering at work, with methodological emphasis on empirical studies of qualitative approach, through case studies. Most of the work was provided by researchers in the Southeast and national references were the most used. It was possible, from the conclusions reached in the paper, to draw an overview of the academic literature on the topic of personnel management, and as well illustrate the topics of interest to researchers and methodological framework of the research in the area.
\end{abstract}

Keywords: Analysis; Scientific Production; Personnel Management; Labor Relations.

\section{Topic: Recursos Humanos}

Reviewed anonymously in the process of blind peer

Dartagnan Ferreira de Macêdo

Universidade Federal de Alagoas, Brasil

http://lattes.cnpq.br/2025788330054193

dartagnan1@outlook.com

Railson Silva Oliveira

Universidade Federal de Alagoas, Brasil

http://lattes.cnpq.br/2117996384813301

railsonoliveira@hotmail.com

João Antônio da Rocha Ataide

Universidade Federal de Alagoas, Brasil

http://lattes.cnpq.br/2042481889198567

admjoaoataide@gmail.com
Received: 16/06/2016

Approved: 23/11/2016

Carolina Maria Ferreira Gomes

Universidade Federal de Alagoas, Brasil

http://lattes.cnpq.br/3074045209401339

carolmariagf@gmail.com

Júlio Marcel dos Santos

Universidade Federal de Alagoas, Brasil

http://lattes.cnpq.br/8154129781066367

juliomarcelsantos@gmail.com

Antônio Carlos Silva Costa

Universidade de São Paulo, Brasil

http://lattes.cnpq.br/2370112735730975

acscosta@uol.com.br

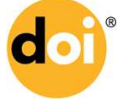

DOI: 10.6008/SPC2179-684X.2016.003.0005
Referencing this:

MACÊDO, D. F.; OLIVEIRA, R. S.; ATAIDE, J. A. R.; GOMES, C. M. F ; SANTOS, J. M.; COSTA, A. C. S... Gestão de pessoas e relações de trabalho: análise da produção científica publicada nos anais dos ENGPR. Revista Brasileira de Administração Científica, v.7, n.3, p.6580, 2016. DOI: http://doi.org/10.6008/SPC2179-684X.2016.002.0005 


\section{INTRODUÇÃO}

O crescimento das organizações possui relação direta com o desenvolvimento das pessoas que as integram. Essa constatação levou os pesquisadores da administração a debruçarem-se sobre o tema, e os resultados apontaram a imprescindibilidade de se buscar, nas empresas, uma conciliação entre as expectativas da organização e das pessoas. Desse modo, seus integrantes tendem a desempenhar suas funções com mais dedicação e comprometimento, o que contribui decisivamente para a consecução dos objetivos organizacionais.

A área de gestão de pessoas, anteriormente denominada administração de recursos humanos, foi assim renomeada em razão da evolução do pensamento organizacional, que passou a compreender os trabalhadores não como mais um recurso da organização, mas como agentes imprescindíveis para o seu desenvolvimento, cujo gerenciamento adequado possui relação direta com um melhor desempenho das organizações.

A atuação das organizações na gestão de pessoas se modificou bastante ao longo do tempo, principalmente após a globalização, e essa transformação se deve tanto a mudanças no mercado e na organização do trabalho, quanto àquelas decorrentes das relações entre as pessoas e as organizações. Vista inicialmente como uma área funcional da administração, a gestão de pessoas foi posteriormente compreendida como parte integrante de um complexo sistema organizacional. Seu processo evolutivo, de acordo com a abordagem funcionalista, é representado pelas fases operacional, gerencial e estratégica, que se revezam e se sobrepõem nas organizações, dependendo de suas especificidades. No Brasil, essa evolução teve características específicas, conectadas aos momentos históricos vividos (DUTRA, 2006).

O objetivo do presente estudo é analisar a produção acadêmica na área de gestão de pessoas e relações de trabalho por meio dos artigos publicados nos anais dos EnGPR - Encontro de Gestão de Pessoas e Relações de Trabalho. Para isso, foi realizada a coleta das informações dos artigos publicados em todas as edições do evento até 2013, e observados os temas de interesse, os assuntos mais discutidos pelos pesquisadores, o perfil metodológico dos trabalhos, as regiões do país dos autores e as referências usadas.

O artigo está dividido em cinco seções, que incluem esta introdução, a fundamentação teórica, os procedimentos metodológicos adotados, os principais resultados obtidos a partir da análise dos dados e, por fim, as considerações finais, com a abordagem sobre os pontos mais relevantes do estudo.

\section{REVISÃO TEÓRICA}

Uma pesquisa de qualidade em administração passa necessariamente pelo empenho, por parte dos pesquisadores, em mitigar as principais deficiências apontadas por Bertero et al. (1999), como a aplicabilidade duvidosa, o referencial importado, a inclinação funcionalista e a confusão epistemológica. Bertero (2006) defende que, dentre as expectativas quanto à pesquisa em administração no Brasil, estão a de que esta permita um melhor conhecimento da realidade administrativa no país, que se verifiquem os seus 
níveis de originalidade e de distanciamento das teorias estrangeiras, e que se obtenha aplicabilidade prática na melhoria da qualidade da administração nacional.

Estimular o comprometimento da atitude do pesquisador, indicar o potencial de redirecionamento do ensino trazido pela contribuição das tendências mais recentes do pensamento organizacional e enfatizar a reflexão sobre os objetivos do conhecimento gerado pelas pesquisas. Essas são preocupações que se combinam e se reforçam na atividade de todos que produzem e disseminam novos conhecimentos em administração (CAMPOS et al., 2007). Campos et al. (2007) indicam um roteiro bastante útil a ser seguido no desenvolvimento da pesquisa: identificação do "hiato" e das razões para seu estudo, focalização do objeto da curiosidade científica, definição do objetivo e de sua contribuição ao campo do conhecimento, delimitação dos recortes mais atrativos e viáveis do problema, estabelecimento preliminar do método e do caminho a trilhar na pesquisa, e antecipação das dificuldades possíveis e das alternativas para sua superação.

Pesquisar sobre as relações de trabalho no Brasil é compreender que estas tendem a tornarem-se cada vez mais complexas e a preocupação com todas as pessoas que possuem relação com as organizações deve ser priorizada. Conceitos como os de aprendizagem e competência são essenciais no contexto atual da gestão de pessoas, pois há a necessidade de adaptação constante, devido à complexidade das variáveis ambientais e, para isso, é fundamental buscar desenvolver as aptidões e qualidades dos indivíduos e das organizações, com ênfase maior nas competências, que se referem à articulação de conhecimentos, habilidades e atitudes (DUTRA, 2006).

O conceito de competência foi estudado por Fleury et al. (2001), referente às pessoas (competência individual) e às organizações, sendo um conceito ainda não totalmente construído. O desenvolvimento de competências agrega valor não somente para as organizações, mas também para o enriquecimento das pessoas. Sobre esse tema, Dutra (2006) ressalta que "definir com precisão quais são as competências demandadas pela empresa e pela sociedade será um fator essencial para garantir a sustentação de vantagens competitivas e para dar melhor foco aos investimentos em educação", apresentando o importante papel das organizações na observação das demandas necessárias para a obtenção de seus objetivos.

Sobre as duas grandes áreas analisadas nesta pesquisa, Carvalho Neto (2012) afirma que o estudo das Relações de Trabalho estaria voltado para um olhar macro, enquanto a Gestão de Pessoas envolveria uma visão mais micro, relacionando-se ao contexto dos indivíduos. $O$ autor sublinha, porém, que independente da metodologia e do enfoque adotados nos trabalhos, o que traria validade e relevância aos mesmos é a consistência e a coerência apresentadas, observando sempre o contexto da pesquisa. Ambos os campos são relevantes para os estudos organizacionais e, portanto, pode haver uma complementação que contribua efetivamente para as duas áreas, desde que haja um funcionamento adequado de redes de pesquisa. Carvalho Neto et al. (2013) defendem que haja uma maior vinculação entre as temáticas dessas duas grandes áreas, citando o tema liderança como um exemplo dessa integração dos estudos.

Vários são os desafios enfrentados pela produção acadêmica em gestão de pessoas no país, como destacam Mascarenhas et al. (2013) devido à transformação histórica do campo de estudos na área de administração, por vezes tendo uma interdisciplinaridade de temáticas e conteúdo, e em outros momentos 
havendo uma restrição de seu escopo ou transferência de teorias para outras áreas dentro da administração. Corroborando com essa realidade, Sobral et al. (2013) fazem uma distinção entre comportamento organizacional, teoria das organizações e gestão de recursos humanos, afirmando que apesar da distinção entre os três campos, há um compartilhamento entre interesses e temáticas semelhantes entre essas áreas.

Estudos anteriores realizaram levantamentos e análises da área de gestão de pessoas e/ou recursos humanos (TONELLI et al., 2003; CALDAS et al., 2003; BARRETO et al., 2011; ULLRICH et al., 2012; MASCARENHAS; BARBOSA, 2013; GALLON et al., 2013; SILVA, et al., 2013; VENANCIO et al., 2014), ou de temas específicos referentes ao campo de conhecimento e áreas afins, como Comportamento Organizacional, Qualidade de Vida no Trabalho, gerações, prazer e sofrimento no trabalho, assédio moral, e vínculos dos indivíduos com as organizações (SOBRAL et al., 2013; MEDEIROS et al., 2009; CORDEIRO et al., 2013; OLETO et al., 2013; POSSAS et al., 2014; BASTOS et al., 2014).

Outros estudos com abordagem semelhante foram realizados, seja em Administração ou em áreas específicas como: competências no Brasil e na área de gestão de projetos, administração pública, gestão social, marketing interno, gestão estratégica e gestão ambiental e contabilidade gerencial (MACHADO-DASILVA et al., 2008; RIBEIRO; CORRÊA, 2014; SOUZA et al., 2013; CALIXTO et al., 2012; FADUL et al., 2011; HOCAYEN-DA-SILVA et. al, 2008, CASSUNDÉ et al., 2014; TAVARES et al., 2011; LUNA et al., 2014; OLIVEIRA; BOENTE, 2012), os quais também foram usados como referência para a construção deste trabalho.

Uma discussão sobre estudos bibliométricos em Administração no Brasil foi levantada por Teixeira et al. (2013), destacando a evolução quantitativa dos artigos com essa abordagem publicados em administração no país e fazendo uma reflexão acerca do uso da técnica em pesquisas, enfatizando a necessidade dos pesquisadores irem além das categorias de análise determinadas, na busca de gerar conhecimentos relevantes para o desenvolvimento da área específica em estudo e, consequentemente, da administração.

É possível constatar que esse modelo de pesquisa representa uma tendência e é importante para o conhecimento de determinadas áreas dentro da administração e que, de modo geral, observa-se que os trabalhos buscaram verificar os seguintes aspectos: processos metodológicos adotados, perfil epistemológico, referências bibliográficas utilizadas, demografia de autoria, redes de colaboração entre os pesquisadores, as temáticas mais preponderantes, entre outros tópicos referentes à produção bibliográfica.

As citações e o fator de impacto dos periódicos em administração foram objeto de estudo de Machado-da-Silva (2008). Vergara et al. (2001) analisaram as referências mais utilizadas nos artigos sobre estudos organizacionais, havendo destaque para as de língua inglesa. Já o estudo de Oliveira e Boente (2012) analisou trabalhos em contabilidade gerencial e buscou verificar quais os estados brasileiros com maior produtividade e qual a proporcionalidade de referências internacionais e nacionais nos artigos, constatando um equilíbrio. Uma análise abrangente acerca das temáticas dos trabalhos publicados nos anais dos EnAPGS - Encontro de Administração Pública e Governança - foi realizada por Fadul et. al (2013), observando a pertinência dos trabalhos publicados no evento à área do conhecimento. 
O campo do Comportamento Organizacional foi analisado por Sobral et al. (2013) em relação às temáticas e aos procedimentos metodológicos utilizados. Contatou-se uma grande diversidade de temas estudados e uma maior preocupação aos aspectos de qualidade na metodologia dos trabalhos mais recentes. É possível observar uma grande aproximação entre as áreas do comportamento organizacional, gestão de pessoas e relações de trabalho, pois conteúdos referentes à aprendizagem, diversidade, estresse e qualidade de vida, liderança, competências, entre outros, são abordados de maneira expressiva por ambas as áreas de conhecimento.

Sobre o nível de interlocução acadêmica, Ullrich et al. (2012) concluíram que no Brasil há pouca interação entre os autores da área em termos de colaboração e formação de redes de publicação, mesmo considerando uma quantidade significativa de pesquisadores. $O$ trabalho de Calixto et al. (2012) também analisou as redes entre os autores, além de uma análise quantitativa das temáticas dos trabalhos na área de competências na gestão de projetos. Caldas et. al (2003) analisaram a área de recursos humanos a partir dos artigos publicados na década de 1990 nos anais dos EnANPAD, observando citações, autores e instituições que mais publicaram, entre outros pontos.

Uma análise da produção acadêmica em recursos humanos durante a década de 1990 no Brasil foi realizada por Tonelli et al. (2003), usando os anais dos EnANPAD e os principais periódicos nacionais. Como principais resultados, observou-se um crescimento nas publicações da área, embora a parte metodológica tenha sido considerada frágil, havendo predominância de estudos de caso que ilustravam teorias já consolidadas. Além disso, a maior parte dos trabalhos concentrava-se em determinadas localidades, de acordo com os programas de pós-graduação no país.

O trabalho de Barreto et. al (2011) estudou a gestão de pessoas a partir de oito temáticas emergentes: gestão estratégica de pessoas, gestão da diversidade, gestão de talentos, gestão de pessoas internacional, aprendizagem organizacional, responsabilidade social, gestão de gerações e modalidades de trabalho flexível, destacando que os conteúdos foram diversificados e, em relação aos aspectos metodológicos das publicações analisadas, foram mais frequentes a abordagem quantitativa e estudos teórico-empíricos.

Ao estudarem parte da produção acadêmica nos anais do EnANPAD, por meio dos descritores "gestão de pessoas" e "recursos humanos", Venâncio et al. (2014) perceberam que houve uma tendência de os trabalhos mais recentes aparecem com a terminologia gestão de pessoas, ao invés de recursos humanos. Os autores concluíram ainda que houve uma predominância de estudos qualitativos e bibliográficos, com foco na dimensão organizacional, e que livros foram bastante usados como fonte de pesquisa.

A produção acadêmica sobre gestão internacional de recursos humanos foi analisada por Silva et al. (2013) por meio de periódicos e artigos publicados em eventos, observando se os trabalhos foram de fontes nacionais ou internacionais, a temática principal e uma análise da metodologia empregada nesses estudos. Gallon et al. (2013) realizaram uma análise dos estudos de gestão de pessoas na área de produção e organizações, por meio de um levantamento de artigos em dois eventos da ANPAD, verificando que há uma 
concentração dos estudos nas seguintes temáticas: gestão por competências, aprendizagem organizacional, qualidade de vida no trabalho e educação, treinamento e desenvolvimento.

Mascarenhas et al. (2013) analisaram a produção científica brasileira em gestão de pessoas destacando o estado da arte na área, considerando apenas periódicos de impacto em virtude da opção de menos artigos, pois possibilitaria uma análise mais aprofundada dos conteúdos. Foram observados o referencial teórico, a contribuição, a metodologia e a discussão, sendo identificadas algumas fragilidades que já haviam sido ilustradas em trabalhos anteriores, como o de Toneli et al. (2003), que indicou o produtivismo acadêmico como uma das possíveis causas da pequena mudança verificada no cenário. Caldas et al. (2003) afirmam que os problemas existentes podem ser resolvidos pelos próprios pesquisadores, por meio de um maior rigor na qualidade dos trabalhos e métodos.

\section{METODOLOGIA}

O presente estudo empreende uma análise abrangente sobre os artigos nas áreas de Gestão de Pessoas e Relações de Trabalho, a partir da produção científica publicada nos anais dos EnGPR. Para isso, foi realizada a coleta de dados dos artigos publicados nas edições do evento até 2013, que é específico para trabalhos nesse campo do conhecimento, totalizando 440 artigos, sendo 120 (2007), 113 (2009), 115 (2011) e 92 (2013).

A escolha de analisar os eventos da divisão específica ocorreu pelo fato de os trabalhos estarem concentrados apenas nas áreas temáticas objeto do presente estudo. Partiu-se ainda do pressuposto de que as publicações em grandes eventos científicos, como os organizados pela Associação Nacional de PósGraduação e Pesquisa em Administração - ANPAD, revelam o que de mais recente está sendo produzido pelos pesquisadores e acadêmicos, interessados especificamente nos temas de interesse determinados pela coordenação do evento. A coleta e posterior análise dos dados buscou identificar os seguintes aspectos nos trabalhos pesquisados: (1) Áreas temáticas ou campo de estudos; (2) Perfil metodológico; (3) Autoria; e (4) Referências utilizadas. Para uma melhor compreensão, a seguir serão detalhados os objetivos do estudo de cada um dos pontos analisados.

As áreas temáticas foram organizadas de acordo com os temas de interesse aos quais os trabalhos submetidos deveriam estar enquadrados, considerando as informações disponibilizadas no site do evento, na edição de 2013. Nas edições anteriores, com exceção da primeira em 2007, outros temas foram propostos pela organização do evento, de modo geral bastante semelhante à última atualização. Logo, para estabelecer um padrão e possibilitar uma análise mais abrangente e homogênea, optou-se por utilizar a versão mais recente que aborda os seguintes temas: Gestão de Pessoas, Relações de Trabalho e Comportamento Organizacional; Trabalho e Diversidade; Gestão de Carreiras; Mudanças e Permanências nas Relações de Trabalho; Liderança; Prazer e Sofrimento no Trabalho; Trabalho, Gestão e Subjetividade; Políticas, Modelos e Práticas de Gestão de Pessoas; Conhecimento e Aprendizagem; e Competências. Foi incluída a categoria "outros" para os trabalhos que não se enquadravam em nenhuma das dez áreas anteriores. Como alguns artigos encaixavam-se em mais de um tema, uma leitura cuidadosa do título, resumo, métodos, 
considerações finais e referências utilizadas foi realizada para enquadrar o trabalho na área temática mais predominante no conteúdo do trabalho. Logo após os conteúdos foram organizados, com o objetivo de posteriormente analisar quais os assuntos mais abordados dentro de cada tema e, assim, delimitar as teorias e discussões mais recorrentes nos estudos da área de gestão de pessoas.

Em relação à análise do perfil metodológico dos trabalhos, a pesquisa baseou-se no trabalho de Sobral e Mansur (2013), que utilizou os seguintes critérios para avaliar a metodologia empregada nos artigos: tipo de publicação (puramente teórico ou se adotou alguma pesquisa de campo empírica); abordagem da pesquisa (quantitativa, qualitativa ou ambas); estratégia de pesquisa (se tratava-se de estudo de um caso ou de casos múltiplos, ou de um levantamento ou survey); e procedimentos de coleta (quais instrumentos usados para coletar os dados: entrevistas, documentos, questionários, ou outros).

Quanto à autoria dos trabalhos, basicamente observou-se a região do país onde as instituições de ensino às quais os autores estão vinculados se localizavam, de forma a mensurar a distribuição dos pesquisadores brasileiros em relação à área de gestão de pessoas. As publicações de 2007 a 2011 não informavam a afiliação dos autores. Para obtenção das informações necessárias, foi realizada uma busca pelos nomes de cada um dos autores no Currículo Lattes, disponibilizado no site do CNPQ. Nos poucos casos em que não havia informações suficientes sobre o currículo do autor, ou estas não estavam disponíveis na plataforma, uma busca no Google foi realizada e, por meio de outras publicações, foi possível encontrar todos os dados dos autores pesquisados.

A análise das referências utilizadas nos trabalhos restringiu-se à mensuração da quantidade de citações usadas nos estudos e à análise da proporcionalidade das referências publicadas em língua portuguesa e em outros idiomas, principalmente em língua inglesa.

Os pontos principais de todos os artigos foram lidos e posteriormente categorizados por apenas um pesquisador, para evitar possíveis vieses de interpretações divergentes acerca das informações coletadas. Logo após, a análise foi feita conjuntamente pelos pesquisadores, onde os conteúdos foram debatidos e interpretados. Os dados coletados foram organizados em uma planilha eletrônica (EXCEL 2010) para posterior tabulação dos dados e análise tanto quantitativa, por meio de mensuração e descrição, quanto qualitativamente, pela análise do conteúdo das temáticas dos trabalhos.

\section{RESULTADOS E DISCUSSÃO}

\section{Áreas de estudo em Gestão de Pessoas e Relações de Trabalho}

Numa análise preliminar dos temas estudados nos artigos publicados nos anais dos EnGPR (Tabela 1), observa-se que a temática predominante é a da convergência de estudos entre gestão de pessoas, relações de trabalho e comportamento organizacional, seguida dos estudos sobre prazer e sofrimento no trabalho. Somadas, essas duas categorias representam cerca de $1 / 3$ do total de artigos publicados no período analisado. 
Quadro 1: Temas, conteúdos e quantitativo de artigos publicados por área temática.

\begin{tabular}{|c|c|c|c|c|}
\hline \multicolumn{2}{|c|}{ Temáticas de produção } & \multirow[b]{2}{*}{$\begin{array}{l}\text { Descritores } \\
\text { Convergências entre os quadros teóricos e os pressupostos epistemológicos de gestão } \\
\text { de pessoas, relações de trabalho e comportamento organizacional. Interfaces entre estas } \\
\text { três áreas. Reflexões relativas à gestão de pessoas e relações de trabalho sob a } \\
\text { perspectiva de diferentes autores, epistemes e metodologias. }\end{array}$} & \multirow{2}{*}{$\begin{array}{l}\text { Total } \\
80\end{array}$} & \multirow{2}{*}{$\%$} \\
\hline 1 & $\begin{array}{l}\text { Gestão de Pessoas, Relações } \\
\text { de Trabalho e } \\
\text { Comportamento } \\
\text { Organizacional }\end{array}$ & & & \\
\hline 2 & Trabalho e Diversidade & $\begin{array}{l}\text { Multiplicidade de gêneros (masculinidades e feminilidades). Orientações sexuais. } \\
\text { Gerações. Classes sociais. Cor da pele. Etnias. Religiões. Aparência pessoal. Pessoas com } \\
\text { deficiência. Discriminação. Inclusão e exclusão no trabalho. Estudos interculturais sob } \\
\text { múltiplas perspectivas. }\end{array}$ & 39 & 8,9 \\
\hline 3 & Gestão de Carreiras & $\begin{array}{l}\text { Tendências de carreiras. Valores e carreiras. Carreira e os múltiplos vínculos contratuais. } \\
\text { Expatriação. Carreiras internacionais. Sucessão. Coaching. Mentoring. Ética e carreira. }\end{array}$ & 31 & 7,1 \\
\hline 4 & $\begin{array}{l}\text { Mudanças e Permanências } \\
\text { nas Relações de Trabalho }\end{array}$ & $\begin{array}{l}\text { Novas configurações das relações de trabalho. Mercado de trabalho. Múltiplos vínculos } \\
\text { contratuais. Terceirização. Empregabilidade. Novas modalidades de jornada de trabalho. } \\
\text { Relações sindicais. Responsabilidade social empresarial nas relações de trabalho. }\end{array}$ & 41 & 9,3 \\
\hline 5 & Liderança & $\begin{array}{l}\text { Perspectivas clássicas e críticas sobre liderança. Teorias de liderança. Poder e liderança. } \\
\text { Liderança e cultura. Liderança e identidade. Desenvolvimento de liderança. } \\
\text { Competências em liderança. Lideranças globais. Lideranças socialmente responsáveis. } \\
\text { Dicotomias entre gerente/líder e entre líder/liderados. Novas configurações } \\
\text { organizacionais e liderança. }\end{array}$ & 26 & 5,9 \\
\hline 6 & $\begin{array}{l}\text { Prazer e Sofrimento no } \\
\text { Trabalho }\end{array}$ & $\begin{array}{l}\text { Sentidos e significados do trabalho. Prazer e realização no trabalho. Sofrimento no } \\
\text { trabalho. Estresse. Burnout. Assédio moral. Assédio sexual. Alcoolismo. Drogas. Outras } \\
\text { patologias do trabalho. Gestão da qualidade de vida no trabalho. }\end{array}$ & 63 & 14,3 \\
\hline 7 & $\begin{array}{l}\text { Trabalho, Gestão e } \\
\text { Subjetividade }\end{array}$ & $\begin{array}{l}\text { Transformações do trabalho e suas repercussões nos modos de trabalhar, de ser e de } \\
\text { viver. Trabalho e família. Trabalho e relacionamentos. Mobilidade. Novos contratos } \\
\text { psicológicos. Violência no trabalho. Gestão de si. A experiência de tempo e espaço. } \\
\text { Controle e resistência. Dilemas pessoais. }\end{array}$ & 35 & 8,0 \\
\hline 8 & $\begin{array}{l}\text { Políticas, Modelos e Práticas } \\
\text { de Gestão de Pessoas }\end{array}$ & $\begin{array}{l}\text { Funções de gestão de pessoas. Recrutamento. Seleção. Remuneração. Gestão de } \\
\text { desempenho. Higiene e segurança no trabalho. Clima organizacional. Modelos de gestão } \\
\text { de pessoas. Avaliação de resultados em gestão de pessoas. }\end{array}$ & 38 & 8,6 \\
\hline 9 & $\begin{array}{l}\text { Conhecimento e } \\
\text { Aprendizagem }\end{array}$ & $\begin{array}{l}\text { Gestão do conhecimento. Aprendizagem. Comunicação interna. Transferência e } \\
\text { compartilhamento do conhecimento. Inovação. Criatividade. Treinamento e } \\
\text { desenvolvimento. Iniciativas de educação corporativa. }\end{array}$ & 37 & 8,4 \\
\hline 10 & Competências & $\begin{array}{l}\text { Desenvolvimento de competências. Gestão de pessoas por competências. Competências } \\
\text { individuais. Competências organizacionais. }\end{array}$ & 38 & 8,6 \\
\hline 11 & Outros & Assuntos que não se enquadram em nenhuma dos temas especificados. & 12 & 2,7 \\
\hline \multicolumn{3}{|c|}{ Totais } & 440 & 100,0 \\
\hline
\end{tabular}

Fonte: ANPAD.

Outras temáticas também tiveram quantidade representativa de artigos: mudanças e permanências no trabalho $(9,3 \%)$, trabalho e diversidade $(8,9 \%)$, políticas, modelos e práticas de gestão de pessoas $(8,6 \%)$, competências $(8,6 \%)$ e conhecimento e aprendizagem $(8,4 \%)$. Esses resultados demonstram uma grande variedade na distribuição dos estudos na área de gestão de pessoas e relações de trabalho, apesar da evidente preferência dos pesquisadores por algumas temáticas.

Sob uma análise temporal, a quantidade de artigos apresentou uma redução da primeira edição do encontro (120 artigos) até a mais recente (92 artigos). Essa circunstância pode estar relacionada ao fato de que a primeira edição do evento não trouxe uma delimitação específica dos temas de interesse, limitandose a apresentar duas grandes áreas de estudo, ao contrário do encontro científico de 2013, que assinalou dez áreas temáticas (as mesmas usadas na categorização deste trabalho), desencadeando, assim, uma obrigatoriedade de que os trabalhos apresentados se enquadrassem nessas temáticas. É possível confirmar esse fato na queda ocorrida no número de artigos que não se enquadram em nenhuma das áreas temáticas, de seis e cinco, em 2007 e 2009, respectivamente, para um e nenhum, nas duas últimas edições. Além desse aspecto, observa-se uma maior preocupação dos avaliadores em escolher artigos que tenham realmente ligação teórica com a proposta do encontro, bem como a tendência de busca por uma melhor qualidade dos trabalhos apresentados, o que pode significar um segundo motivo para a diminuição de artigos aprovados. 
O panorama geral de cada uma das categorias temáticas evidencia algumas tendências sobre os conteúdos e teorias prevalentes nos trabalhos. A área temática Gestão de Pessoas, Relações de Trabalho e Comportamento Organizacional aborda teorias convergentes e constitui a que apresenta artigos com os objetivos mais variados. O estudo de vários aspectos do comprometimento organizacional destacou-se como o assunto mais pesquisado dentro do tema. Entre outras abordagens que se destacaram, podem ser citadas mudança organizacional e resistência à mudança, motivação para o trabalho e para o voluntariado, cultura organizacional, questões envolvendo sustentabilidade e responsabilidade socioambiental, vínculos organizacionais e funcionais e a dinâmica entre relações de trabalho, a política de recursos humanos de organizações públicas e privadas e retenção de talentos como vantagem competitiva.

Essas tendências identificadas vêm ao encontro do estudo de Bastos et al. (2014), que observou que as discussões acerca dos vínculos dos indivíduos com a organização estão centradas em quatro temas principais: comprometimento organizacional, contratos psicológicos, cidadania organizacional e percepções de apoio e de justiça e equidade. O tema comprometimento foi o que teve mais destaque, assim como se observou na análise desta pesquisa. Ainda, dentro do estudo comportamental nas organizações, alguns tópicos foram discutidos pelos autores dentro dessa temática como, por exemplo, a teoria do comportamento planejado, fatores atitudinais e comportamentais, controle e flexibilidade nas relações trabalhistas, humor no trabalho e a teoria motivacional da expectativa.

O tema Trabalho e Diversidade teve representatividade significativa e pode ser considerado emergente na administração. As quatro discussões que foram mais preponderantes nos trabalhos relacionam-se às relações de gênero, principalmente assuntos ligados ao poder e as mulheres no mercado de trabalho, atuação das pessoas com deficiência nas organizações, estudo da diversidade de um modo geral, incluindo trabalhos sobre problemas enfrentados por alguns grupos minoritários e discriminação em relação à orientação sexual, raça e portadores de necessidades especiais. Nota-se, ainda, que os debates nessas temáticas também abrangeram a inclusão e a exclusão desses grupos no mercado de trabalho. Ademais, muitos artigos tratavam sobre as relações entre as gerações e, sobre esse assunto, Cordeiro et al. (2013) realizou pesquisa onde a produção brasileira foi encontrada exclusivamente em anais de congressos.

Nos estudos relacionados à Gestão de Carreiras, houve certo equilíbrio entre os conteúdos pesquisados, havendo uma ênfase maior nos trabalhos sobre valores e carreira, tendências de determinadas carreiras como, por exemplo, no setor público e bancário, transição profissional na carreira, múltiplos vínculos contratuais, além de carreiras internacionais, expatriação e repatriação.

O número de artigos sobre Mudanças e Permanências nas Relações de Trabalho foi considerável, enfatizando os estudos que tratam de novas configurações das relações de trabalho e empregabilidade. A análise dos objetivos dos trabalhos também abordou, entre outros pontos, o mercado de trabalho formal e informal, a questão da mão-de-obra, transformação do ambiente de trabalho, representação social do trabalho, terceirização e relações sindicais.

A quantidade de estudos sobre Liderança pode ser considerada baixa, em comparação com os demais. Os principais assuntos debatidos sobre o tema estão centrados em suas teorias e evoluções, com 
destaque para a liderança transformacional. Os estilos de liderança, o papel desempenhado pelos líderes e as relações entre liderança e cultura organizacional também estiveram dentro dos objetivos das pesquisas. Em relação às perspectivas clássicas sobre liderança, observou-se a existência de trabalhos baseados nos estudos da teoria weberiana.

O grande interesse pelo tema Prazer e Sofrimento no Trabalho é perceptível devido à quantidade de artigos apresentados. Analisando os artigos sobre essa temática, Oleto et al. (2013) concluíram que "os sentimentos de prazer e de sofrimento estão relacionados a um híbrido de fatores que, dependendo da subjetividade dos sujeitos, pode transformar-se em uma patologia ou em um meio de ressignificação do sofrimento". Os conteúdos mais pesquisados foram qualidade de vida no trabalho e assédio moral, esse último foi objeto de pesquisa de Possas et al. (2014). Os outros temas mais estudados foram estresse no trabalho, burnout, satisfação ou realização, sofrimento, e sentido e significados do trabalho.

As publicações referentes ao tema Trabalho, Gestão e Subjetividade não tiveram um conteúdo homogêneo que tenha merecido destaque dentre os tópicos tratados, identificando-se uma variedade de estudos que abordaram, principalmente, os temas da violência no trabalho, trabalho e família, mobilidade, dilemas no trabalho, contrato psicológico, trabalho e relacionamentos, e identidade e gestão de si.

No que tange ao tema oito, Políticas, Modelos e Práticas de Gestão de Pessoas, verificou-se um predomínio de estudos sobre a gestão de desempenho, abordando desde técnicas de avaliação de desempenho, como a avaliação 360 graus, quanto analisando o desempenho profissional. Ainda sobre desempenho, a maior parte dos trabalhos que tratavam de salário ou remuneração fazia uma correlação entre ambos, no sentido de incentivar a produtividade e motivação dos funcionários. Destacaram-se, ainda, estudos acerca das funções da gestão de pessoas, gestão estratégica de pessoas, clima organizacional, recrutamento e seleção, e avaliação de resultados em gestão de pessoas.

Dentro do tema Conhecimento e Aprendizagem, os artigos focaram seus estudos na aprendizagem e em seus tipos, seja individual, social ou organizacional. Nogueira e Odelius (2015) identificaram em seu estudo cinco desafios da pesquisa em aprendizagem organizacional, entre eles, a inexistência de uma teoria sobre o assunto e o cuidado necessário com as técnicas e procedimentos metodológicos adotados. Outros conteúdos das pesquisas nessa temática relacionaram-se ao treinamento e desenvolvimento, gestão do conhecimento, transferência e compartilhamento do conhecimento e educação corporativa.

Os estudos sobre competências apresentam um predomínio de pesquisas sobre a gestão de pessoas por competências e os aspectos que exercem influência nas organizações. Entre os demais resultados obtidos, o desenvolvimento de competência também foi explorado, além das teorias sobre competências individuais, organizacionais, coletivas e gerenciais. Ainda, em relação aos artigos classificados na categoria outros, pois não se encaixavam em nenhuma das demais temáticas, os trabalhos tratam de temas diversos, entre eles, empreendedorismo, processo decisório e comunicação organizacional. 


\section{Perfil Metodológico dos Trabalhos}

$\mathrm{Na}$ análise quanto ao tipo de publicação, prevaleceram os artigos empíricos, com mais de $85 \%$ do total. As metodologias que empregam pesquisa de campo, observações-participantes, entrevistas não estruturadas ou depoimentos (qualitativas), e as entrevistas estruturadas, questionários fechados ou enquetes (quantitativas), com avaliações mais conectadas com a realidade prática, parecem agradar mais aos avaliadores do EnGPR. Por outro lado, as reflexões teóricas têm perdido espaço, possivelmente em função da dificuldade dos gatekeepers em identificarem trabalhos com insights teóricos realmente inovadores, capazes de satisfazer elementos essenciais, com evidências convincentes e que representem contribuições efetivas à teoria organizacional (WHETTEN, 2003).

Tabela 1: Tipos de trabalho.

\begin{tabular}{lcc}
\hline Tipo de publicação & Quantidade & \% \\
\hline Teóricos & 63 & 14,3 \\
\hline Empíricos & 377 & 85,7 \\
\hline
\end{tabular}

Nesse contexto, o resultado converge com o sublinhado por Tonelli et al. (2003), onde $81 \%$ dos artigos publicados nos anais dos EnANPAD foram teórico-empíricos. Ainda, registra-se que as entrevistas e os questionários foram os procedimentos de coleta de dados mais utilizados nas pesquisas, seguidos da análise documental e da observação. Dentre os outros procedimentos adotados incluem-se grupos focais, as pesquisas bibliográficas e as experimentais, menos utilizadas nos artigos analisados.

No aspecto da abordagem metodológica, os artigos qualitativos dominaram todas as temáticas pesquisadas, à exceção do tema Prazer e Sofrimento no Trabalho, que apresentou a mesma quantidade de artigos quantitativos. Apesar dos desafios da metodologia, que mesclam benefícios como os "de promover trocas de experiências entre os pesquisadores" e desafios como o "reconhecimento da dimensão imprevisível e inacabada inerente à condição humana" (MANSANO, 2014), a abordagem qualitativa tem sido a preferida das pesquisas sociais aplicadas. Esse resultado vai ao encontro do que foi apontado por Venâncio et al. (2014), que também evidenciou destaque maior para as pesquisas com abordagem qualitativa.

Tabela 2: Procedimentos de coleta de dados usados nas pesquisas empíricas.

\begin{tabular}{|c|c|c|c|c|c|}
\hline Temas & Entrevistas & Questionários & Documentos & Observação & Outros \\
\hline $\begin{array}{l}\text { Gestão de Pessoas, Relações de Trabalho e Comportamento } \\
\text { Organizacional }\end{array}$ & 32 & 36 & 14 & 11 & 3 \\
\hline Trabalho e Diversidade & 24 & 4 & 10 & 6 & 2 \\
\hline Gestão de Carreiras & 20 & 12 & 6 & 3 & 2 \\
\hline Mudanças e Permanências nas Relações de Trabalho & 21 & 11 & 12 & 2 & 1 \\
\hline Liderança & 12 & 11 & 4 & 2 & 1 \\
\hline Prazer e Sofrimento no Trabalho & 24 & 39 & 11 & 4 & 1 \\
\hline Trabalho, Gestão e Subjetividade & 19 & 5 & 5 & 1 & 3 \\
\hline Políticas, Modelos e Práticas de Gestão de Pessoas & 13 & 16 & 12 & 2 & 2 \\
\hline Conhecimento e Aprendizagem & 21 & 15 & 8 & 7 & 1 \\
\hline Competências & 22 & 10 & 13 & 4 & 1 \\
\hline Outros & 8 & 4 & 3 & 1 & 0 \\
\hline TOTAL & 216 & 163 & 98 & 43 & 17 \\
\hline$\%$ & 40,22 & 30,35 & 18,25 & 8,01 & 3,17 \\
\hline
\end{tabular}

Nas pesquisas quantitativas, novamente destacaram-se os temas mais abordados do evento: Gestão de Pessoas, Relações de Trabalho e Comportamento Organizacional, e Prazer e Sofrimento no Trabalho, que 
representaram praticamente a metade do total de pesquisas apresentadas. Merece destaque também o tema Políticas, Modelos e Práticas de Gestão de Pessoas, cujos estudos também apresentam uma relação estreita com o tema geral do EnGPR.

Tabela 3: Abordagem usada nos artigos analisados.

\begin{tabular}{|c|c|c|c|c|c|c|c|c|c|}
\hline \multirow{2}{*}{\multicolumn{2}{|c|}{ Temáticas de produção }} & \multicolumn{8}{|c|}{ Métodos de trabalho } \\
\hline & & \multicolumn{2}{|c|}{ Qualitativos } & \multicolumn{2}{|c|}{ Quantitativos } & \multicolumn{2}{|c|}{ Mistos } & \multicolumn{2}{|c|}{ Teóricos } \\
\hline 1 & Gestão de Pessoas, Relações de Trabalho e Comportamento Organizacional & 26 & $12,5 \%$ & 22 & $20,2 \%$ & 16 & $26,7 \%$ & 16 & $25,4 \%$ \\
\hline 2 & Trabalho e Diversidade & 28 & $13,5 \%$ & 1 & $0,9 \%$ & 3 & $5,0 \%$ & 7 & $11,1 \%$ \\
\hline 3 & Gestão de Carreiras & 17 & $8,2 \%$ & 9 & $8,3 \%$ & 4 & $6,7 \%$ & 1 & $1,6 \%$ \\
\hline 4 & Mudanças e Permanências nas Relações de Trabalho & 20 & $9,6 \%$ & 8 & $7,3 \%$ & 4 & $6,7 \%$ & 9 & $14,3 \%$ \\
\hline 5 & Liderança & 10 & $4,8 \%$ & 9 & $8,3 \%$ & 2 & $3,3 \%$ & 5 & $7,9 \%$ \\
\hline 6 & Prazer e Sofrimento no Trabalho & 19 & $9,1 \%$ & 26 & $23,9 \%$ & 14 & $23,3 \%$ & 4 & $6,3 \%$ \\
\hline 7 & Trabalho, Gestão e Subjetividade & 24 & $11,5 \%$ & 5 & $4,6 \%$ & 0 & $0,0 \%$ & 6 & $9,5 \%$ \\
\hline 8 & Políticas, Modelos e Práticas de Gestão de Pessoas & 15 & $7,2 \%$ & 14 & $12,8 \%$ & 5 & $8,3 \%$ & 4 & $6,3 \%$ \\
\hline 9 & Conhecimento e Aprendizagem & 20 & $9,6 \%$ & 10 & $9,2 \%$ & 3 & $5,0 \%$ & 4 & $6,3 \%$ \\
\hline 10 & Competências & 23 & $11,1 \%$ & 5 & $4,6 \%$ & 5 & $8,3 \%$ & 5 & $7,9 \%$ \\
\hline & Outros & 6 & $2,9 \%$ & 0 & $0,0 \%$ & 4 & $6,7 \%$ & 2 & $3,2 \%$ \\
\hline \multicolumn{2}{|c|}{ Totais/percentuais específicos } & 208 & $47,3 \%$ & 109 & $24,8 \%$ & 60 & $13,6 \%$ & 63 & $14,3 \%$ \\
\hline \multicolumn{2}{|r|}{ Total } & 440 & & & & & & & \\
\hline
\end{tabular}

Os estudos de caso, únicos e múltiplos, representaram mais de dois terços das estratégias de pesquisa utilizadas nos artigos analisados, o que permite concluir que esse recurso de ensino e de produção do conhecimento permanece predominante na Administração, bem como, segundo Yin (2010, p. 20), em todas as áreas acadêmicas. $O$ terço remanescente refere-se basicamente a estudos embasados em survey ou levantamentos, já que a estratégia do experimento só foi utilizada em um único artigo dentre todos os analisados.

Tabela 4: Estratégias utilizadas nas pesquisas empíricas.

\begin{tabular}{|c|c|c|c|c|c|c|c|}
\hline \multicolumn{2}{|c|}{ Temáticas de produção } & \multicolumn{2}{|c|}{ Estudos de caso } & \multicolumn{2}{|c|}{ Levantamentos ou survey } & \multicolumn{2}{|c|}{ Experimentos } \\
\hline 1 & Gestão de Pessoas, Relações de Trabalho e Comportamento Organizacional & 44 & $17,3 \%$ & 20 & $16,5 \%$ & - & $0,0 \%$ \\
\hline 2 & Trabalho e Diversidade & 21 & $8,2 \%$ & 11 & $9,1 \%$ & - & $0,0 \%$ \\
\hline 3 & Gestão de Carreiras & 19 & $7,5 \%$ & 11 & $9,1 \%$ & - & $0,0 \%$ \\
\hline 4 & Mudanças e Permanências nas Relações de Trabalho & 23 & $9,0 \%$ & 9 & $7,4 \%$ & - & $0,0 \%$ \\
\hline 5 & Liderança & 13 & $5,1 \%$ & 8 & $6,6 \%$ & - & $0,0 \%$ \\
\hline 6 & Prazer e Sofrimento no Trabalho & 39 & $15,3 \%$ & 20 & $16,5 \%$ & - & $0,0 \%$ \\
\hline 7 & Trabalho, Gestão e Subjetividade & 21 & $8,2 \%$ & 8 & $6,6 \%$ & - & $0,0 \%$ \\
\hline 8 & Políticas, Modelos e Práticas de Gestão de Pessoas & 17 & $6,7 \%$ & 16 & $13,2 \%$ & 1 & $100,0 \%$ \\
\hline 9 & Conhecimento e Aprendizagem & 25 & $9,8 \%$ & 8 & $6,6 \%$ & - & $0,0 \%$ \\
\hline 10 & Competências & 23 & $9,0 \%$ & 10 & $8,3 \%$ & - & $0,0 \%$ \\
\hline & Outros & 10 & $3,9 \%$ & - & $0,0 \%$ & - & $0,0 \%$ \\
\hline \multicolumn{2}{|c|}{ Totais } & 255 & $100,0 \%$ & 121 & $100,0 \%$ & 1 & $100,0 \%$ \\
\hline \multicolumn{2}{|c|}{$\%$} & \multicolumn{2}{|c|}{$67,6 \%$} & \multicolumn{2}{|c|}{$32,1 \%$} & \multicolumn{2}{|c|}{$0,3 \%$} \\
\hline
\end{tabular}

\section{Autoria e Referências}

A análise da origem das publicações demonstra que a preocupação sobre o tema de Gestão de Pessoas e Relações do Trabalho continuam concentradas na Região Sudeste brasileira, que contribuiu com mais da metade de tudo que foi publicado nas últimas quatro edições do EnGPR. Por outro lado, a Região Nordeste tem ampliado significativamente sua participação na produção do conhecimento nessas áreas da Administração, e já publica tanto quanto tradicionalmente prolífica Região Sul. Surpreendentemente, a Região Centro-Oeste aparece com poucas contribuições ao evento de gestão de pessoas da ANPAD, e a participação da Região Norte é praticamente inexistente. 
Dessa forma, uma das inferências do presente trabalho é que a concentração observada nos autores potencializa o problema da desconexão da produção acadêmica com a realidade brasileira, do paroquialismo que ameaça não permitir mudanças na produção acadêmica brasileira, bem como da "perpetuação das mazelas do produtivismo" (BERTERO et al, 2013, p. 192). Também, o maior número de trabalhos publicados nas regiões apontadas pode estar relacionado a quantidade de programas de pós-graduação consolidados nesses locais, o que pode significar a existência de grupos de pesquisa que estejam alinhados com a área de gestão de pessoas.

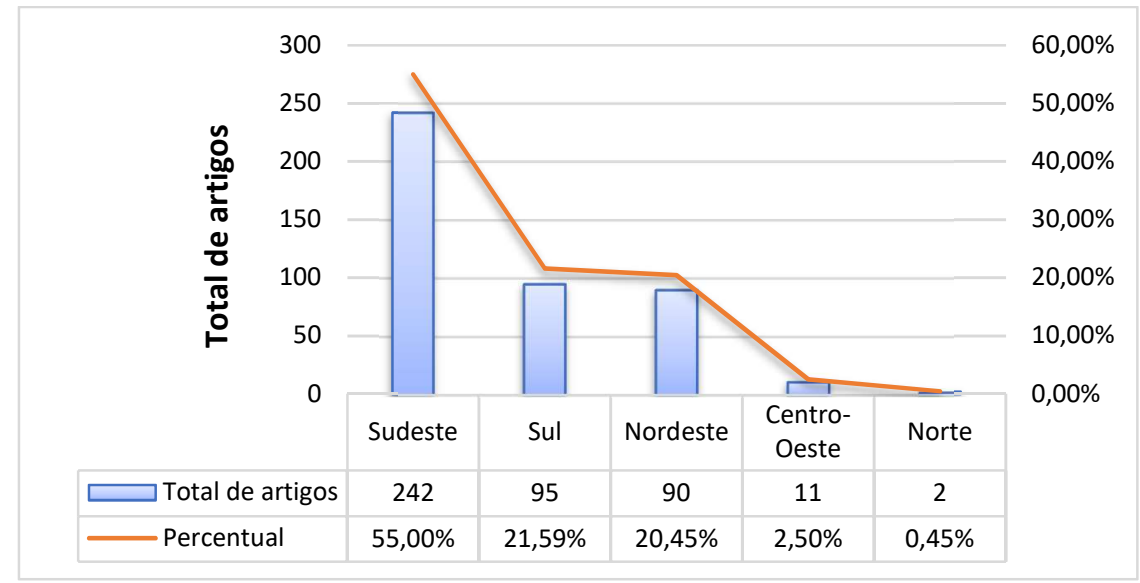

Figura 1: Autoria dos trabalhos por região do país.

No que tange às referências e citações, os artigos dos eventos privilegiaram o referencial em língua portuguesa sobre o estrangeiro, na proporção de dois terços por um. Valmorbida et al. (2013), ao avaliar as publicações nacionais e internacionais acerca do tema específico da Avaliação de Desempenho, apontaram que há pouquíssimas citações nos artigos nacionais, quando comparados aos estrangeiros. É possível desatacar, ainda, que a maioria das referências estrangerias usadas estão em língua inglesa, havendo, com participação menor, trabalhos em espanhol e francês, dependendo da temática de estudo.

Tabela 5: Referências usadas nos artigos.

\begin{tabular}{llll}
\hline Referências usadas & Total & Média & $\%$ \\
\hline Português & 9.560 & 2.390 & $67,0 \%$ \\
\hline Estrangeiras & 4.716 & 1.179 & $33,0 \%$ \\
\hline Total & 14.276 & $\mathbf{3 . 5 6 9}$ & $100,0 \%$ \\
\hline
\end{tabular}

Quanto aos conteúdos dos artigos, foram identificados problemas intrincados e limitações estruturais do desenvolvimento da produção acadêmica, generalização nas citações e nas fontes, pulverização das fontes e diversidade de referências, com concentração em alguns autores, conforme já identificado por Caldas et al (2003) em pesquisa acerca de publicações em Recursos Humanos realizadas na década de 1990.

\section{CONCLUSÕES}

O presente artigo buscou apresentar e analisar o que vem sendo produzido no campo de gestão de pessoas e relações de trabalho, por meio de um levantamento dos artigos publicados nos anais do EnGPR, observando as temáticas preponderantes, os procedimentos metodológicos adotados, além da localização 
geográfica dos pesquisadores e a origem das referências que basearam as pesquisas. Os resultados permitem um conhecimento mais abrangente sobre as duas grandes áreas de conhecimento objeto de estudo deste trabalho, contribuindo para o desenvolvimento de futuras pesquisas.

Ficou evidenciada uma grande variedade de temáticas estudadas, com ênfase nos estudos acerca das relações entre o comportamento organizacional, gestão de pessoas e as relações de trabalho, especialmente trabalhos sobre comprometimento, e também sobre o tema prazer e sofrimento no trabalho, abordando mais expressivamente os temas assédio moral e qualidade de vida no trabalho. Houve ainda representatividade significativa nos trabalhos relacionados a mudanças e permanências nas relações de trabalho, trabalho e diversidade, competências, políticas modelos e práticas de gestão de pessoas, e conhecimento e aprendizagem.

Quanto ao perfil metodológico, percebeu-se que há uma maior predominância de trabalhos empíricos, qualitativos, por meio de estudos de caso, e que utilizam entrevistas e questionários como principais métodos de coleta de dados. Em relação à autoria dos trabalhos, a maioria concentra-se na região Sudeste do Brasil, e as regiões Sul e Nordeste tem participação semelhante nas pesquisas da área. Analisando as referências usadas pelos autores, observou-se que a maior parte se baseia em outros estudos de autores em língua portuguesa, porém também há um número significativo de obras em outros idiomas, principalmente em língua inglesa, que contribuíram para os trabalhos.

Por fim, observa-se que a definição clara dos objetivos relacionados às pesquisas sobre as temáticas de interesse das áreas de gestão de pessoas e relações de trabalho parece proporcionar uma oportunidade importante para a análise, tanto de temas tradicionalmente tratados nos estudos da Administração, quanto para conteúdos emergentes. Nesse sentido, a necessidade de identificação das tendências das pesquisas organizacionais se reveste de grande importância, levando-se em conta que cumprem um papel essencial em auxiliar-nos a perceber o direcionamento que os produtores de conhecimento em Administração estão imprimindo ao estado da arte nesse campo de conhecimento.

Como limitações deste trabalho, aponta-se o processo de categorização das temáticas, visto que não há um padrão entre os autores que realizaram estudos anteriores em relação às categorias e aos critérios adotados, minimizando a possibilidade de comparação dos resultados. Também, o estudo restringiu-se aos artigos publicados em um importante evento nacional. Para pesquisas futuras, sugere-se a realização de novas pesquisas que abranjam as áreas de gestão de pessoas e relações de trabalho, de modo a acompanhar e ilustrar o processo evolutivo dos estudos realizados pelos pesquisadores.

\section{REFERÊNCIAS}

BARRETO, L. M. T. S.; SILVA, M. P.; FISCHER, A. L.; ALBUQUERQUE, L. G.; AMORIM, W. A. C.. Temas Emergentes em Gestão de Pessoas: Uma análise da produção acadêmica. Rev. Adm. UFSM, Santa Maria, v.4, n.1, p.215-232, 2011.

BASTOS, A. V. B; RODRIGUES, A. C. A; MACAMBIRA, M. O.; BORGES-ANDRADE, J. E. Vínculos dos Indivíduos com a Organização: Análise da Produção Científica Brasileira 2000-
2010. Psicologia: Teoria e Pesquisa, v.30, n.2, p.153-162, 2014.

BERTERO, C. O.. Ensino e Pesquisa em Administração. Mazon: Thomson South-Western, 2006.

BERTERO, C. O.; ALCADIPANI, R.; CABRAL, S.; FARIA, A.; ROSSONI, L.. Os desafios da produção do conhecimento em 
Administração no Brasil. Cadernos EBAPE, Rio de Janeiro, v.11, n.1, p.181-196, 2013.

BERTERO, C. O.; CALDAS, M. P.; WOOD JR., T.. Produção Científica em Administração de Empresas: provocações, insinuações e contribuições para um debate local. Revista de Administração de Empresas, Rio de Janeiro, v.3, n.1, p.147178, 1999.

CALDAS, M. P.; TINOCO, T.; CHU, R. A.. Análise bibliométrica dos artigos de RH publicados no ENANPAD na década de 1990: um mapeamento a partir das citações dos heróis, endogenias e jactâncias que fizeram a história da produção científica da área. In: EnANPAD. Anais. Atibaia: ANPAD, 2003.

CALIXTO, G. M.; FURLAN, P. K.; CARVALHO, M. M.. Estudo das tendências na análise de competências na gestão de projetos através de técnicas de bibliometria. Revista de Gestão e Projetos - GeP, São Paulo, v.3, n.1, p.181-196, 2012.

CAMPOS, A. M. S. M.; COSTA, I. S. A.. Espaços e caminhos para a pesquisa em administração: estimulando a prática da reflexividade. Revista de Administração Pública, Rio de Janeiro, p.37-48, 2007.

CARVALHO NETO, A.. Relações de Trabalho e Gestão de Pessoas: Entre o macro e o micro? Provocações epistemológicas. REGE, São Paulo, v.19, n.2, p.299-308, 2012.

CARVALHO NETO, A.; SANT'ANNA, A. S.. Relações de Trabalho e Gestão de Pessoas, Dois Lados de Uma Mesma Moeda: Vinculações Sob a Ótica do Fenômeno da Liderança. Revista Gestão \& Tecnologia, Pedro Leopoldo, v.13, n.2, p.220, 2013.

CASSUNDÉ, F. R. S. A.; JUNIOR, N. F. C.; FARIAS, S. A.; MENDONÇA, J. R. C. O Que Tem se Falado por aí sobre Marketing Interno?: Um Estudo sobre a Produção Brasileira na Área de Administração. Brazilian Business Review, Vitória, v.11, n.5, p.51-73, 2014.

CORDEIRO, H. T. D.; FREITAG, B. B.; FISCHER, A. L.; ALBUQUERQUE, L. G. A questão das gerações no campo da gestão de pessoas: tema emergente? Revista de Carreiras e Pessoas, São Paulo, v.3, n.2, p.2-18, 2013.

DUTRA, J. S.. Gestão De Pessoas: modelos, processos, tendências e perspectivas. São Paulo: Atlas, 2006.

FADUL, E.; SILVA, L. P.; CERQUEIRA, L. S.. Análise do campo da administração pública através da produção científica publicada nos anais dos ENAPGS. Cadernos Gestão Pública e Cidadania, São Paulo, v.16, n.59, 2011.

FLEURY, M. T. L.; FLEURY, A.. Construindo o conceito de competência. RAC, p.183-196, 2001.

GALLON, S.; BITENCOURT, B. M.; CAMILLIS, P. K.; SCHEFFER, A. B. B.. Gestão de pessoas: o que andam falando por aí?: uma metanálise sobre os estudos de gestão de pessoas na área de produção. Sociais e Humanas, Santa Maria, v.26, n.3, p.588-607, 2013.
HOCAYEN-DA-SILVA, A. J. ROSSONI, L.; FERREIRA JÚNIOR, I. Administração pública e gestão social: a produção científica brasileira entre 2000 e 2005. Revista de Administração Pública, Rio de Janeiro, v.42, n.4, p.655-680, 2008.

LUNA, R. A.; SILVA, L. F. A.; MOURA, A. R. Um estudo bibliométrico sobre as publicações em periódicos acadêmicos na temática gestão ambiental. Revista Científica Hermes, n.12, p.137-153, 2014.

MACHADO-DA-SILVA, C. L.; FILHO, E. R. G.; ROSSONI, L.; GRAEFF, J. F. Periódicos Brasileiros de Administração: Análise bibliométrica de impacto no triênio 2005-2007. RACEletrônica, Curitiba, v.2, n.3, p.351-373, 2008.

MANSANO, S. R. V. O método qualitativo nos estudos sociais aplicados: dimensões éticas e políticas. Revista Economia \& Gestão, Belo Horizonte, v.14, n.34, p.119-136, 2014.

MASCARENHAS, A. O.; BARBOSA, A. C. Q.. Produção Científica Brasileira em Gestão de Pessoas no período 20002010. RAE, São Paulo, v.53, n.1, p.35-45, 2013.

MEDEIROS, J. P.; OLIVEIRA, J. A.. Uma viagem à produção científica em Qualidade de Vida no Trabalho (QVT) nos anos 2001 a 2005: estudo nos anais do ENANPAD. Revista Eletrônica de Ciência Administrativa, v.8, n.1, p.31-43, 2009.

NOGUEIRA, R. A.; ODELIUS, C. C. Desafio da pesquisa em Aprendizagem Organizacional. Cad.EBAPE.BR, Rio de Janeiro, v.13, n.1, p.83-102, 2015.

OLETO, A. F.; MELO, M. C. O. L.; LOPES, A. L. M.. Análise Bibliométrica da Produção Sobre Prazer e Sofrimento no Trabalho nos Encontros da Associação Nacional de PósGraduação em Administração (2000-2010). Psicologia: Ciência e Profissão, Brasília, v.33, n.1, p.60-73, 2013.

OLIVEIRA, E. K. F.; BOENTE, D. R.. Análise bibliométrica da produção científica recente sobre contabilidade gerencial. Organizações em contexto, São Bernardo do Campo, v.8, n.15, 2012

POSSAS, M. C.; MEDEIROS, C. R. O.; BARROSO, A. S.. Análise epistemológica da produção bibliográfica sobre assédio moral no campo da administração. Revista UNIFAMMA, v.13, 2014.

RIBEIRO, H. C. M.; CORRÊA, R.. Estado da arte da revista de administração Mackenzie: análise da produção científica de 2008 a 2012. Revista Gestão Universitária da América Latina - GUAL, Florianópolis, v.7, n.2, p.152-174, 2014

SILVA, N. B.; ORSI, A.; NAKATA, L. E.. Análise da Produção Acadêmica sobre Gestão Internacional de Recursos Humanos entre 2001 e 2011. ReCaPe - Revista de Carreiras e Pessoas, São Paulo, v.3, n.3, 2013.

SOBRAL, F. J. B. A.; MANSUR, J. A.. Produção Científica Brasileira em Comportamento Organizacional no período 2000-2010. Revista de Administração de Empresas, São Paulo, v.53, n.1, p.21-34, 2013.

SOUZA, D. L.; ZAMBALDE, A. L.; FERRUGINI, L.; CASTRO, C. C.. O Campo de Estudos sobre Competências no Brasil: Características e Limitações. In: ENCONTRO DE GESTÃO DE PESSOAS E RELAÇÕES DE TRABALHO, 4. Anais. Brasília: 2013. 
TAVARES, R. S. C. R.; KAMIMURA, Q. P.; ARAÚJO, E. A. S.. Análise da Produção Científica de Artigos sobre Gestão Estratégica: um Estudo Bibliométrico. In: SIMPÓSIO DE EXCELÊNCIA EM GESTÃO E TECNOLOGIA, 3. Anais. 2011.

TEIXEIRA, M. L. M.; IWAMOTO, H. M.; MEDEIROS, A. C. Estudos bibliométricos (?) em Administração: discutindo a transposição de finalidade. Administração: Ensino e Pesquisa, Rio de Janeiro, v.14, n.3, p.423-452, 2013.

TONELI, M. J.; CALDAS, M. P.; LACOMBE, B. M. B.; TINOCO, T.. Produção acadêmica em recursos humanos no Brasil: 1991-2000. RAE, v.43, n.1, 2003.

ULLRICH, D. R.; OLIVERIA, J. S.; SCHEFFER, A. B. B.. Formação de redes sociais de coautoria na área de gestão de pessoas: uma análise bibliométrica em periódicos brasileiros no triênio de 2007 a 2009. REGE, São Paulo, v.19, n.4, p.553570, 2012.

VALMORBIDA, S. M. I.; ENSSLIN, S. R.; ENSSLIN, L.. Avaliação de desempenho na administração de Universidade Pública:
Análise bibliométrica da literatura nacional e internacional. Administração Pública e Gestão Social, v.5, n.3, p.116-125, 2013.

VENÂNCIO, D. M.; MARTINS, C.; DUTRA, A.; STEINBACH, A.. Análise da produção científica sobre gestão de pessoas nos anais do Encontro Nacional da Associação de Pós-Graduação em Administração - (ENANPAD) de 2001 a 2010. Revista de Administração da UNIMEP, v.12, n.2, 2014.

VERGARA, S. C.; PINTO, M. C. S.. Referência Teóricas em Análise Organizacional: um Estudo das Nacionalidades dos Autores Referenciados na Literatura Brasileira. RAC, v.5, p.103-121, 2001.

WHETTEN, D. A.. O que constitui uma contribuição teórica? Revista de Administração de Empresas, Rio de Janeiro, v.43, n.3, p.69-73, 2003.

YIN, R. K.. Estudo de caso: planejamento e métodos. 4 ed. Porto Alegre: Bookman, 2010. 